\title{
¿EL DERECHO DE DEFENSA: UNA GARANTÍA QUE REALM ENTE SE RESPETA?
}

\author{
Sylvia Amelia Torres Morales de Ferreyros*
}

\begin{abstract}
Resumen
El presente trabajo busca llamar la atención sobre la problemática que se presenta cuando se pretende ejercer uno de los derechos fundamentales que está claramente reconocido en nuestra Constitución: El derecho de defensa. Hoy en día no podemos negar que, a pesar de contar con conceptos claros sobre este derecho: "Todos tenemos derecho a una defensa" y "Todos son considerados inocentes hasta que no se pruebe su culpabilidad" (presunción de inocencia"), estamos muy lejos de garantizar de manera legítima que todo ello se cumpla.

El trabajo explorará la regulación de este derecho y los problemas que encontramos que lo contaminan y que se yerguen como constantes obstáculos para que éste pueda ser adecuadamente ejercido.
\end{abstract}

Palabras Clave: Derecho de defensa, culpabilidad.

\section{Abstract}

The present work intent to highlight the problematic that appears when it is tried to exert one of the fundamental rights that clearly it is recognized in our Constitution: The Right of Defense.

Nowadays we can not deny that despite of the fact that we count on clear concepts on the right: "We all have the right to a defense" and "We all are innocent until proven guilty (innocence presumption"), we are very far from guaranteeing in a legitimate way that all this is fulfilled.

The work will explore the regulation of this rights and the problems that we found that contaminates and appear like constant obstacles so that this one can suitably be exerted.

Key words: The Right of Defense, guilt.

\section{Sumario}

1. Introducción. 2. El derecho de defensa: ¿cómo se entiende? 3. El derecho de defensa en nuestro ordenamiento jurídico. 4 . El derecho de defensa en los tratados internacionales de derecho humanos. 5. El derecho de defensa en las constituciones andinas. 6. Derecho de defensa: principales problemas que observamos.

* Directora del Programa de Derecho de la Universidad Femenina del Sagrado Corazón y profesora de la misma Facultad. Socia del Estudio Torres y Torres Lara y Asociados - Abogados. 


\section{INTRODUCCIÓN}

Nadie puede cuestionar la naturaleza esencial y fundamental del llamado "derecho de defensa" el mismo que existe para garantizar la protección de la libertad o los intereses de un procesado.

El constitucionalista Enrique Bernales Ballesteros ${ }^{1}$, señala que el derecho de defensa cuenta con tres características:

a) Es un derecho constitucionalmente reconocido, cuyo desconocimiento invalida el proceso.

b) Convergen en él una serie de principios procesales básicos: la inmediación, el derecho a un proceso justo y equilibrado, el derecho de asistencia profesionalizada y el derecho de no ser condenado en ausencia.

c) El beneficio de la gratuidad.

Así, al parecer, el derecho de defensa, se encuentra estrechamente ligado a un principio fundamental, cual es el de la igualdad. Y es por ello, que a través de las tres características anteriormente citadas, se pretende, de alguna forma, buscar un equilibrio entre las partes de un proceso.

Sin embargo, cabe hacerse el cuestionamiento siguiente que justamente es objeto de la presente investigación: Pese a contar con los conceptos muy claros, ¿se encuentra garantizado en nuestro país el derecho de defensa?

\section{EL DERECHO DE DEFENSA : ¿CÓMO SE ENTIENDE?}

La "defensa" en un sentido lato, se entiende como aquel derecho, reconocido constitucionalmente, que tiene toda persona, de solicitar ante un órgano de justicia, una solución justa ante un determinado litigio. Aquí se presenta el problema del individuo a quien supuestamente se le ha lesionado un derecho, por lo que deberá recurrir a la justicia para efectuar su reclamo, conforme a una garantía constitucional que va avalar dicha reclamación.

En un sentido más estricto y específicamente dentro de la esfera penal, debemos decir que mediante la "defensa", las partes deberán estar en la posibilidad -tanto en el plano jurídico como en el fáctico- de ser convocadas para ser escuchadas, y colocarse frente al Sistema en una formal contradicción con "igualdad de armas" siendo pues -como lo señala Julio Maier-, "una garantía frente al Poder del Estado y representa una limitación del poder estatal".2 
Podemos señalar que el derecho de defensa presenta una serie de características que, para efectos del presente trabajo, debemos tener claramente en cuenta:

1. Es un derecho reconocido constitucionalmente.

2. Comprende una serie de derechos derivados o conexos como:

a) Conocer los fundamentos de la imputación.

b) Conocer los motivos de la detención (esto con la finalidad de que pueda ser defendido de manera eficaz, contando con todos los elementos de juicio).

c) El derecho de no ser condenado en ausencia.

d) Derecho a una justicia penal gratuita y, con ello, la garantía de la defensa de oficio para aquellas personas que no cuenten con los recursos suficientes para ejercer plenamente su derecho de defensa.

e) Derecho a impugnar las resoluciones judiciales que lo perjudiquen.

f) Derecho a valerse de su propio idioma.

g) Derecho a guardar silencio y a no ser obligado a declarar contra su voluntad (en este aspecto, entra a tallar, el tema de las torturas que, a todas luces, no pueden permitirse por tratarse de una vulneración flagrante a los derechos humanos).

h) En general, todo aquello que se respete y ajuste a un debido proceso, que permita que el derecho de defensa sea debidamente ejercitado.

Ahora bien, no obstante que, como observamos la defensa es un derecho fundamental de todo ciudadano, nada obliga a éste a ejercerlo. Así, si por ejemplo, una persona es demandada y no hace nada para defenderse, no podríamos decir que se está vulnerando su derecho de defensa, ya que éste no es ejercido por la propia voluntad del demandado/agraviado, por lo que podemos señalar que se trata más bien de una cuestión de oportunidad.

Como podemos inferir, el derecho de defensa, tiene estrecha relación con los principios fundamentales que garantizan la seguridad y la igualdad ante la ley, principios que se encuentran consagrados en los textos constitucionales democráticos. El derecho de defensa pretende, de alguna forma, buscar un equilibrio entre las partes de un proceso. Por una parte, el poder acusador del lado de la mano del Fiscal y, por el otro, el inculpado ejerciendo su derecho de defensa en forma adecuada; logrando de esta forma, conseguir la tan ansiada igualdad que debe prevalecer por encima de todo, por cuanto sin ella, nunca podremos decir que el valor justicia se ha llegado a alcanzar. 
En relación a este igualdad debemos decir que en el campo del Derecho de Familia, podemos confundirnos y pensar en que tal igualdad no se da para ambas partes, puesto que en muchos casos se favorece a una de ellas, pero se trata de la parte más débil de la relación; así podemos entender que lo que busca la ley -con esta "presunta desigualdad"- es equiparar poderes entre la parte más favorecida y la menos favorecida, llegando finalmente a una real igualdad entre ambas, lo que podría asimilarse a la figura de la discriminación llamada "positiva".

\section{EL DERECHO DE DEFENSA EN NUESTRO ORDENAMIENTO JURÍDICO}

Consideramos interesante hacer un breve recuento de cómo aparece el derecho de defensa a lo largo de nuestra historia constitucional ${ }^{3}$ :

\subsection{CONSTITUCIONES}

a. Constitución de Cádiz de 1812: El capítulo III de la referida Constitución, que alude a la administración de justicia en lo criminal, establece algunas normas que pueden considerarse como antecedentes del derecho de defensa:

"Artículo $287^{\circ}$.- Ningún español podrá ser preso, sin que preceda información sumaria del hecho, por el que merezca según la ley ser castigado con pena corporal, y asimismo, un mandamiento del juez por escrito, que se le notificará en el acto mismo de la prisión.

Artículo $290^{\circ}$.- El arrestado, antes de ser puesto en prisión, será presentado al juez ...para que reciba la declaración...

Artículo $300^{\circ}$.- Dentro de las veinte y cuatro horas se manifestará al tratado como reo la causa de su prisión y el nombre de su acusador si lo hubiere.

Artículo $302^{\circ}$.- El proceso de allí en adelante será público en el modo y forma en que determinen las leyes.

Artículo $303^{\circ}$.- No se usará del tormento ni de los apremios."

b. Constitución Politica de 1823: En este texto legal, encontramos referencias -aunque no claras y directas- del derecho de defensa, en dos partes: 
1. Capítulo VIII, referido al Poder Judiciario:

"Artículo 106.- Los códigos civil y criminal prefijarán las formas judiciales. Ninguna autoridad podrá abreviarlas, ni suspenderlas en caso alguno.

Artículo 107.- En las causas criminales el juzgamiento será público, el hecho reconocido y declarado por jurados y la ley aplicada por los Jueces. Artículo 117.- Dentro de las 24 horas se le hará saber a todo individuo, la causa de su arresto, y cualquiera omisión en este punto se declara atentatoria de la libertad individual".

2. Capítulo V, referido a las Garantías Constitucionales:

"Artículo 193.- Sin embargo de estar consignados los derechos sociales e individuales de los peruanos en la organización de esta ley fundamental se declaran inviolables: (...)

Inciso 9).- La igualdad ante la ley, ya premia, ya castigue."

c. Constitución Política de 1826: En este texto, también se observa en dos partes, antecedentes del derecho de Defensa:

1) Capítulo V, referido a la Administración de Justicia:

“Artículo 117.- Ningún peruano puede ser preso sin precedente de la información del hecho, por el que merezca pena corporal, y un mandamiento escrito del juez ante quien ha de ser presentado...

Artículo 118.- Acto continuo, si fuera posible deberá dar su declaración sin juramento, no defiriéndose ésta en ningún caso por más tiempo que el de 48 horas.

Artículo 120.- En las causas criminales el juzgamiento será público: reconocido el hecho y declarado por Jurados (cuando se establezcan); y la ley aplicada por los jueces.

Artículo 121.- No se usará jamás el tormento, ni se exigirá confesión al reo."

2. Capítulo XI, referido a las Garantías:

"Artículo 142.- La libertad civil, la seguridad individual, la propiedad y la igualdad ante la ley, se garantizan a los ciudadanos por la Constitución."

d. Constitución de 1828: En el caso del presente texto legal, presentan antecedentes del derecho de Defensa, los siguientes Títulos:

1. Título VIII: De la Administración de Justicia

“Artículo 123.- Las causas criminales se harán por Jurados. La institución de éstos se detallará por una ley. Entre tanto los jueces conocerán haciendo 
el juzgamiento público, y motivando sus sentencias.

Artículo 126.- Ningún Tribunal o Juez puede abreviar ni suspender en caso alguno las formas judiciales.

Artículo 127.- Ninguno puede ser preso sin precedente información del hecho ...y sin mandamiento por escrito, del Juez competente ...la declaración del preso por ningún caso puede diferirse más de 48 horas.

Artículo 129.- Quedan abolidos:

1. El juramento en toda declaración y confesión de causa criminal sobre hecho propio (...)

3. El tormento."

2. Título IX: Disposiciones Generales:

“Artículo 149.- La Constitución garantiza la libertad civil, la seguridad individual ante la ley ...

Artículo 157.- Todos los peruanos son iguales ante la ley, ya premie, ya castigue."

e. Constitución de 1834: Adicionalmente a las disposiciones establecidas en los textos anteriores, la presente Constitución, contiene lo siguiente:

“Artículo 126.- Ningún ciudadano está obligado a dar testimonio contra sí mismo en causa criminal bajo su juramento u otro apremio...

Artículo150.- Ninguno puede ser condenado si no es juzgado legalmente."

f. Constitución de 1839.- Contiene las mismas disposiciones que el anterior texto constitucional, en lo que a antecedentes del derecho de defensa se refiere.

g. Constitución de 1856.- En este texto, se coloca el Título de las Garantías Individuales en cuarto lugar, omitiéndose el capítulo correspondiente a la Administración de Justicia. Lo referente al Poder Judicial, resulta siendo general y tratado sólo en 10 artículos.

Dentro de las garantías Individuales, tenemos:

“Art.18.- Nadie podrá ser arrestado sin mandato escrito de juez competente, o de la autoridad encargada del orden público...

Artículo 31.- Las leyes protegen y obligan igualmente a todos..." 
h. Constituciones de 1860 y 1867.- Contienen las mismas disposiciones que el texto de 1856.

i. Constitución de 1920.- Contiene una disposición interesante y distinta a las citadas anteriormente, la establecida en el Capítulo destinado a las Garantías Individuales, que dice :

“Artículo 28.- Nadie puede defender o reclamar su derecho sino en la forma que establezca o autorice la ley. El derecho de petición puede ejercerse individual o colectivamente."

Observamos que por primera vez, se hace alusión al término "defensa".

j. Constitución de 1933.- El texto de 1933, recoge, por primera vez, la disposición que contiene el principio de legalidad, en su artículo 57 ..."Nadie será condenado por acto $\mathrm{u}$ omisión que al tiempo de cometerse no estén calificados en la ley de manera expresa e inequívoca como infracciones punibles, ni juzgado sino por los tribunales que las leyes establezcan. Carece de valor toda declaración obtenida por la violencia..."

Resulta importante señalar que la alusión al término "defensa" que se establecía en el artículo $28^{\circ}$ del texto de 1920 , fue retirada del texto de 1933, quedando sólo la referencia a la forma de ejercer (individual o colectivamente) el derecho de petición.

k. Constitución de 1979.- Es, a partir de la Constitución de 1979, cuando se coloca a la persona en un estadío especial y fundamental. Por ello, el Título I, Capítulo I, trata los derechos y deberes de la persona, capítulo que en su artículo $2^{\circ}$, inciso 20), contiene disposiciones relativas al derecho de defensa como:

d) Nadie será procesado ni condenado por acto u omisión que al tiempo de cometerse no esté previamente calificado en la ley, de manera expresa e inequívoca, como infracción punible, ni sancionado por pena no prevista en la ley.

f) Toda persona es considerada inocente mientras no se haya declarado judicialmente su responsabilidad.

g) Nadie puede ser detenido sino por mandamiento escrito y motivado del Juez o por las autoridades policiales en flagrante delito. En todo caso el detenido debe ser puesto, dentro de veinticuatro horas o en el término de la distancia, a disposición del Juzgado que corresponde. 
Se exceptúan los casos de terrorismo, espionaje y tráfico ilícito de drogas en los que las autoridades policiales pueden efectuar la detención preventiva de los presuntos implicados por un término no mayor de quince días naturales, con cargo de dar cuenta al Ministerio Público y al Juez, quien puede asumir jurisdicción antes de vencido el término.

h) Toda persona será informada inmediatamente y por escrito de la causa o razones de su detención. Tiene derecho a comunicarse y ser asesorado con un defensor de su elección desde que es citado o detenido por la autoridad.

i) Nadie puede ser incomunicado sino en caso indispensable para el esclarecimiento de un delito y en la forma y el tiempo previsto por la ley. La autoridad está obligada a señalar sin dilación el lugar donde se halla la persona detenida, bajo responsabilidad.

j) Las declaraciones obtenidas por la violencia carecen de valor. Quien la emplea incurre en responsabilidad penal.

k) Nadie puede ser obligado a prestar juramento ni compelido a declarar o reconocer culpabilidad en causa penal contra si mismo, ni contra su cónyuge ni sus parientes dentro del cuarto grado de consanguinidad o segundo de afinidad.

Por otro lado, el artículo $233^{\circ}$, referido a las garantías de la administración de justicia, consagra, en su inciso 9) de manera clara y directa, el derecho de defensa al señalar:

Artículo $233^{\circ}$.- Son garantías de la administración de justicia: (...)

Inciso 9) .- La de no ser penado sin juicio ni privado del derecho de defensa en cualquier estado del proceso. El Estado provee la defensa gratuita a las personas de escasos recursos.

l. Constitución de 1993: Nuestro actual y vigente texto constitucional contiene asimismo, las normas detalladas anteriormente, tanto en lo que a los derechos de las personas se refiere, consagrados en el artículo $2^{\circ}$, inciso 24), como también en las garantías de la Administración de Justicia, en su artículo $139^{\circ}$, inciso 14 ).

Por otra parte, es importante señalar que nuestra actual Ley Orgánica del Poder Judicial hace alusión al derecho de defensa, en su artículo $7^{\circ}$, al señalar que "en el ejercicio y defensa de sus derechos, toda persona goza de la plena tutela jurisdiccional, con las garantías de un debido proceso." Asimismo, destina un Capítulo al tema de la Defensa Gratuita (artículos. 295 y ss.). 
Observamos pues, luego de haber citado las distintas normas que atañen a nuestro ordenamiento legal, que el derecho de defensa se encuentra enraizado - por lo menos en los textos de las distintas normas- como una garantía fundamental que busca la protección de la libertad o los intereses de un procesado.

\section{EL DERECHO DEDEFENSA EN LOSTRATADOSINTERNACIONALES DE DERECHOS HUMANOS}

El derecho de defensa se encuentra reconocido en los instrumentos internacionales de derechos humanos.

En lo que al sistema universal se refiere, la Declaración Universal sobre Derechos Humanos, lo consagra en sus artículos $3^{\circ}$ y 1.1., donde establece el acceso a la justicia sin discriminación y el derecho de toda persona a que se aseguren las garantías necesarias para su defensa, respectivamente.

Por su parte, el Pacto Internacional de Derechos Civiles y Políticos, consagra el derecho de defensa en el ámbito penal, al señalar en su artículo $14^{\circ} 3 . b$ que toda persona acusada de un delito tiene la garantía mínima de disponer del tiempo y de los medios adecuados para la preparación de su defensa y a comunicarse con un defensor de su elección. Asimismo, el referido pacto, incorpora, como garantía mínima, el derecho de toda persona a la asistencia jurídica gratuita, si careciere de medios suficientes para pagarlo.

Asimismo, el derecho de defensa, se encuentra igualmente reconocido en la Declaración Americana sobre Derechos y Deberes del Hombre, documento que en su artículo XXVI, segundo párrafo, establece lo siguiente: "toda persona acusada de delito tiene derecho a ser oída en forma imparcial y pública."

Finalmente, la Convención Americana sobre Derechos Humanos, protege el derecho de defensa, dentro del marco de las garantías judiciales contempladas en el artículo 8, reconociendo a toda persona el derecho, en plena igualdad, a ciertas garantías mínimas, entre las que se menciona el hecho de conceder al inculpado el tiempo y los medios adecuados para la preparación de su defensa; el derecho de defenderse personalmente o ser asistido por un defensor a su elección y; el derecho irrenunciable a ser asistido por un defensor público.

\section{EL DERECHO DE DEFENSA EN LAS CONSTITUCIONES ANDINAS}

A nivel de las Constituciones del área Andina, podemos afirmar que el derecho de defensa, se encuentra claramente consagrado, constituyéndose como en nuestro caso, en una garantía fundamental de todo ordenamiento 
que se afirme democrático. A continuación, se presentará un cuadro donde se aprecian las normas constitucionales atinentes:

\begin{tabular}{|c|c|c|}
\hline PAÍs & $\begin{array}{c}\text { ARTÍCULO } \\
\text { CONSTITUCIÓN }\end{array}$ & DETALLE DE LA NORM A \\
\hline BOLIVIA & Artículo $16^{\circ}$ & $\begin{array}{l}\text { Se reconoce el carácter inviolable del derecho de defensa } \\
\text { en un proceso judicial. Asimismo la necesidad de } \\
\text { asistencia letrada desde el momento de detención del } \\
\text { inculpado. }\end{array}$ \\
\hline CHILE & Artículo $19^{\circ}$ & $\begin{array}{l}\text { Asegura a todas las personas el derecho a la defensa } \\
\text { jurídica en la forma que la ley señale, no existiendo } \\
\text { impedimento o restricción alguna por parte de autoridad } \\
\text { o persona cualquiera. }\end{array}$ \\
\hline COLOMBIA & $\begin{array}{l}\text { Artículos } 29^{\circ} \text { y } \\
229^{\circ}\end{array}$ & $\begin{array}{l}\text { Reconoce a los inculpados el derecho a la defensa y a } \\
\text { la asistencia de un abogado escogido por él o de oficio, } \\
\text { durante la investigación y el juzgamiento. Se establece el } \\
\text { deber de reglamentar por ley los supuestos en los que la } \\
\text { persona puede acceder a la administración de justicia sin } \\
\text { representación de abogado, no limitando el acceso a la } \\
\text { administración de justicia mediante la defensa cautiva. }\end{array}$ \\
\hline ECUADOR & Artículo $24^{\circ}$ & $\begin{array}{l}\text { Establece que nadie podrá ser privado del derecho } \\
\text { de defensa en ningún estado o grado del respectivo } \\
\text { procedimiento. No se podrá efectuar interrogatorio } \\
\text { alguno sin la asistencia de un abogado defensor; la } \\
\text { contravención de esta disposición priva de eficacia } \\
\text { probatoria a cualquier diligencia que se efectúe. } \\
\text { El Estado establecerá defensores públicos para el } \\
\text { patrocinio de las comunidades indígenas, de los } \\
\text { trabajadores, de las mujeres y de los menores de edad } \\
\text { abandonados o víctimas de violencia intrafamiliar o } \\
\text { sexual, y de toda persona que no disponga de medios } \\
\text { económicos. }\end{array}$ \\
\hline \multirow[t]{2}{*}{ PERU } & $\begin{array}{l}\text { Artículo } 139^{\circ} \\
\text { inc. } 14 \text { y } 16^{\circ}\end{array}$ & $\begin{array}{l}\text { Reconoce el derecho de defensa como un principio y } \\
\text { derecho de la función jurisdiccional. Nadie puede ser } \\
\text { privado del derecho de defensa en ningún estado del } \\
\text { proceso. Asimismo, establece el derecho a la defensa } \\
\text { gratuita para las personas de escasos recursos y para } \\
\text { todos, en los casos que la ley señala. }\end{array}$ \\
\hline & $\begin{array}{l}\text { Artículo } 49^{\circ} \\
\text { inciso } 1\end{array}$ & $\begin{array}{l}\text { La defensa y la asistencia jurídica son derechos } \\
\text { inviolables en todo estado y grado de la investigación y } \\
\text { del proceso. Toda persona tiene derecho a ser notificada } \\
\text { de los cargos por los cuales se le investiga, de acceder } \\
\text { a las pruebas y de disponer del tiempo y de los medios } \\
\text { adecuados para ejercer su defensa }\end{array}$ \\
\hline
\end{tabular}

Fuente: Teleley. 
Por otro lado, debemos señalar que si bien es cierto, parece un consenso que el derecho de defensa debe ser respetado y bien ejercido, en otro tipo de ordenamientos legales, más lejanos a nuestra idiosincracia, parece haberse comprendido e interiorizado más profundamente, significando una mayor garantía para los individuos. En este sentido, podemos mencionar, por ejemplo un caso que se ventiló en la Corte Suprema de los Estados Unidos, donde se dejó en libertad a un sentenciado, bajo el argumento que su derecho de defensa no había sido eficientemente ejercido por cuanto, a pesar de contar con un abogado defensor, éste lo habría representado tan ineficientemente que finalmente resultó perjudicado.

Cabe reflexionar sobre el caso presentado: parece pues tener lógica y total sentido, pero ¿resulta aplicable en nuestro ordenamiento legal? La respuesta resulta evidente: difícilmente un procesado podría alegar una representación ineficiente y obtener por ello, una absolución.

Sin embargo, no debemos dejar de mencionar que, así como existen en otras legislaciones casos en que se observa claramente un respeto irrestricto por el derecho de defensa, también se presentan mecanismos que atacan a su operatividad como por ejemplo el llamado "plea bargaining", que consiste en privar al acusado de un juicio mediante su reconocimiento de culpabilidad, conviniendo una pena con el Fiscal, sanción que finalmente, el Tribunal no podrá aumentar aunque sí disminuir, e incluso llegar a una absolución.

Este mecanismo se ha convertido en una suerte de "panacea" con el único fin de obtener sentencias con mayor celeridad. Es de esta forma en que el defensor y, básicamente el "público" recibe presiones constantes para que se aplique este método y los procesados, teniendo en cuenta la situación terrible que viven dentro de los establecimientos penitenciarios, no dudan un instante en declararse culpables, aunque ello no signifique recuperar su libertad de inmediato. ¿Aquí, está garantizado el derecho de defensa? Y si el procesado se niega a "convenir" con el Fiscal, ¿qué sucedería? Como ejemplo de ello, citamos un caso ocurrido en Filadelfia (USA): el 9 de marzo del año 2001, el juez Joel Lazarus, condenó a Lionel Tate, de 14 años de edad, a cadena perpetua sin fianza, por haber dado muerte, -cuando contaba con 12 años- a una amiga de nombre Tiffany Eunick, durante una imitación de luchadores profesionales. El adolescente, su madre y su abogado defensor habían rechazado antes del juicio el ofrecimiento del fiscal de tres años de cárcel, un año de arresto domiciliario y diez años de libertad bajo fianza, a cambio del reconocimiento de su culpabilidad. Al parecer, la diferencia entre la pena finalmente expuesta y la ofrecida bajo el procedimiento de plea bargaining, se obedeció al deseo del inculpado de ejercer su derecho a un juicio justo. 
Este hecho nos demuestra que todos los sistemas tienen sus fallas, por lo que debemos tender a subsanar dichas fallas, en beneficio de una búsqueda real de la justicia.

\section{DERECHO DE DEFENSA: PRINCIPALES PROBLEMAS QUE OBSERVAMOS}

No podemos, de forma alguna, negar un hecho: el derecho de defensa en nuestro país, no se encuentra plenamente garantizado. Y esta terrible verdad se debe a varios motivos, entre los cuales podemos destacar los siguientes:

1. El derecho de defensa no se respeta, desde sus inicios; es decir que desde el momento mismo de la detención por parte de la policía, se viene violando esta garantía constitucional.

Para muestra, un botón: El Instituto de Defensa Legal, realizó una encuesta ${ }^{4}$ sobre: "Detención e Investigación Policial", habiéndose obtenido los siguientes resultados alarmantes:

a) ¿El derecho de defensa ejercido a través de un abogado se respetó durante la detención?

$\begin{array}{ll}\text { SÍ: } & 3.57 \% \\ \text { NO: } & 96.42 \%\end{array}$

b) ¿El derecho de defensa ejercido a través de un abogado se respetó durante el interrogatorio?

$\begin{array}{ll}\text { Sí: } & 3.57 \% \\ \text { NO: } & 96.42 \%\end{array}$

c) ¿El ofrecimiento de la defensa de oficio por el Ministerio Público se respetó?

SI: $\quad 2 \%$

NO: $\quad 98 \%$

Este es un problema fundamental y quizá se lo debemos a la filosofía de nuestra policía que, en ocasiones, considera -erróneamente- que en todos los casos se está tratando con delincuentes convictos y confesos que no merecerían-según su criterio- ningún tipo de garantía. Muchos de nuestros miembros de las fuerzas policiales no conciben que al "detenido" se le 
presume inocente, hasta que no se pruebe su culpabilidad. Observamos que, lamentablemente, en muchos casos, sucede lo contrario, se le considera culpable, hasta que se pruebe su inocencia.

Pero, también entendemos que el Perú, ha estado sometido durante muchos años al "terror" que infundieron los grupos senderistas, por lo que definitivamente, en el plano psicológico, debemos aceptar que nuestras fuerzas policiales, difícilmente podrán olvidar las consecuencias de hechos abominables cometidos en esta época de terror $y$, por lo tanto, en muchas ocasiones, los actos policiales reflejan ese rencor y revancha que aún no pueden desterrar de sus almas.

2. Gratuidad en el acceso a la Justicia.

Invocar la gratuidad en el acceso de la justicia resulta tan lírico como invocar la gratuidad en el acceso a la educación.

Es cierto que si un procesado no cuenta con recursos suficientes para proveerse de una defensa de tipo privada, el Estado está en la obligación de asignarle un Defensor de Oficio. Al parecer, con ello, todo estaría solucionado, pero ¿podemos hablar de "gratuidad" en todo el sentido estricto de la palabra? ¿No es el procesado quien tendrá que hacer frente a las costas del juicio, que nada tiene que ver con los honorarios del abogado defensor?.

La educación es gratuita -reza el precepto-, pero ¿no es cierto que los colegios estatales, exigen ciertos pagos pro determinados derechos? iy no exigen también, acaso, que el niño cuente con ciertos útiles escolares? ¿no es cierto que de nada vale que un niño asista a clases, si no tiene una lapicero y un cuaderno donde escribir? Esto, ciertamente, no es costeado por el Estado.

¿Por ello, podemos hablar de una completa gratuidad?

3. Defensoría de Oficio.

Sin tratar de desmerecer de forma alguna, el esfuerzo que realizan los defensores de oficio, ¿podríamos afirmar categóricamente, sin temor a equivocarnos, que se encuentra en igual condición un procesado representado por un defensor de oficio que un procesado representado por un defensor privado?. 
Lamentablemente, en nuestro país, aún no se ha desarrollado un adecuado sistema de defensa pública que pueda satisfacer las necesidades de los más pobres, por lo que arribamos a una terrible apreciación: "La libertad de una persona puede depender de su capacidad económica." Y esto sin contar que, si se piensa que el acusado es culpable, como anticipadamente suele sospecharse, la conclusión se resume a: ¿qué sentido tiene que se le defienda, y sobre todo con dinero del Estado?. Así ...."esta íntima convicción...se traduce en un trato casi irrespetuoso hacia la actividad de la defensa." ${ }^{5}$

4. Prejuicios que atentan contra el principio de la presunción de inocencia y por lo tanto con el derecho de defensa: Los Medios de Comunicación.

Si bien es cierto este punto se ha tratado cuando comentábamos el tema (prejuiciolatenteencontra del detenido)dela detención policial,es másgrave aún cuando ha pasado de la esfera policial a otros niveles, cometiéndose graves injusticias, donde se involucran directa o indirectamente, hasta a la propia familia del procesado.

En un proceso, donde la presunción de culpabilidad es la que prima, definitivamente, no puede ejercerse el derecho de defensa en iguales condiciones. Muchos de estos casos, desprovistos de completa razón, son claramente motivados por prejuicios incomprensibles y lo que es peor, por el temor cobarde a no tomar una posición discrepante con la mayoría.

Debemos preguntarnos: ¿la prensa, muchas veces, no contribuye frontalmente a generar en el público una idea errada de los acontecimientos? ¿no efectúa acaso una pre-valorización de los hechos? ¿no escuchamos a diario que tal o cual persona "habría" matado a alguien; "habría" robado a alguien, "habría" violado a alguien; etc, etc.? Bajo el escudo del lenguaje condicional, muchos medios de comunicación -en un afán sensacionalistadilapidan el honor de las personas sin esperar siquiera la existencia de pruebas contundentes que ayuden a sostener las distintas hipótesis que se suelen manejar y presentar a la ciudadanía. Pero, mientras tanto, la persona ya fue juzgada y sentenciada por los medios de comunicación, sentencia que acarrea la deshonra no solo del involucrado sino también la de su familia.

Ante este caso nos preguntamos ¿tiene la prensa, avalada en el llamado "derecho a la información" y a la tan mentada "libertad de expresión", la facultad de atropellar los derechos fundamentales de las personas, como por 
ejemplo el de la presunción de inocencia y, con ello entorpecer el legítimo derecho a ejercer su defensa sin la contaminación que los medios generan día a día al brindar un noticia de manera irresponsable, carente de sustento y por qué no decirlo, en muchos casos, con grandes dosis de morbosidad?

Lo cierto es que la sentencia judicial es el único elemento que puede lograr el rompimiento del principio de la presunción de inocencia y señalar a determinada persona como autor de un delito. En la medida de que dicha sentencia no exista, no puede permitirse que otros vulneren este derecho fundamental. En este sentido, existe profusa jurisprudencia española que ha señalado lo siguiente: "no es admisible, pues, que una noticia publicada en un medio de información pueda calificar a una persona como "autor de un delito de estafa" en el momento de la detención de esa persona, dado que el único acto que puede quebrar dicha presunción de inocencia del acusado en nuestro ordenamiento es la sentencia del tribunal que declara la autoría del delito, y tal resolución judicial, obviamente no existía en el momento de publicarse la noticia de la detención"

El principio de la presunción de inocencia, le impone al periodista severas normas de conducta para la elaboración de las informaciones judiciales cuyo enfoque y redacción deben dejar en el lector, oyente o televidente la idea de que los acusados no necesariamente son culpables, sino que deben presumirse inocentes. Lamentablemente, muchos periodistas hacen caso omiso de estas normas y consideran -como ya lo hemos mencionado líneas arriba- que al exponer la noticia en lenguaje condicional ya cumplieron con no dilapidar al acusado, sabiendo perfectamente que el interlocutor que recibe la noticia, no entiende que este tipo de lenguaje no es definitivo.

Consideramos que, pese a que el derecho a la información se encuentra consagrado en nuestro texto constitucional, en su artículo $2^{\circ}$, inciso 4 ), no puede ser ejercido si con ello entran en colisión otros derechos fundamentales como lo son: el de presunción de inocencia y el derecho al honor, y asimismo, influye en que el derecho de defensa no pueda ser ejercido con total objetividad. La libertad de información no es ilimitada, como tampoco lo es ninguna otra libertad. No afirmamos que no se debe informar, sino que se informe con conciencia y, sobre todo, con responsabilidad. Así ..."lo que se pide a los profesionales es que vivan la honestidad profesional, desglosada en dos requisitos indispensables: no intencionalidad en el relato y juego limpio en el comentario..."7 Obviamente el comentario de una persona es completamente libre, si embargo, deberá ser lo más objetivo posible, de manera tal que permita la posibilidad de la formación de otras opiniones. 
Sylvia Amelia Torres Morales - ¿El derecho de defensa: una garantía que realmente se respeta?

Está, en juego, mucho más que el derecho de la persona a ser debidamente informada, por encima de ello, se encuentra la dignidad y el honor del "presunto autor" de un "presunto delito".

A manera de reflexión final, podemos señalar que en la medida que los ciudadanos no tomen real conciencia de que vivimos en una sociedad con prejuicios, y, asimismo, no asuman que es responsabilidad colectiva apoyar para que estos prejuicios no contaminen el ejercicio de los derechos fundamentales de las personas, la labor de nuestra administración de justicia no avanzará, se verá constantemente obstaculizada y todo ello redundará en un solo hecho: el declive moral de una sociedad que -como la nuestra- exige, necesita y clama, día a día, por una inyección de valores que la haga cada vez más digna y justa.

1 Bernales, E. La Constitución de 1993. Lima: CIEDLA, 1996, p. 656

2 Cita efectuada por informe del Estudio Torres y Torres Lara-Abogados. "El derecho de Defensa"; en Teleley: www.asesor.com.pe/teleley

3 Ugarte Del Pino, J. Historia de las Constituciones del Perú. Lima: Andina, 1978.

4 Datos obtenidos de informe elaborado por el Estudio Torres y Torres Lara-Abogados, ya citado anteriormente.

5 Martinez, S. ¿Quién defiende a la defensa?: el derecho de defensa como requisito inexcusable de una administración de justicia respetuosa de los derechos humanos. En: La administración de justicia : en los albores del tercer milenio / coord. por Julio Andrés Sampedro Arrubla, Ana Messuti. Editorial Universidad, 2001. P. 168

6 Sentencia del Tribunal Constitucional Español del 3 de diciembre de 1992; citado en QUISPE FARFAN, Fany. La libertad de declarar y el derecho a la no incriminación. Lima, Palestra Editores, 2002, Op. Cit. P. 71

7 Martinez, J. Efectos de la tecnología electrónica sobre la comunicación periodística. Citado en Romero Coloma, Aurelia María. Libertad de Información frente a otros derechos en conflicto: Honor, intimidad y presunción de inocencia. Madrid: Civitas, 2000, p. 91 